\title{
The Effects of Alcohol Consumption on Restaurant Tipping
}

\author{
Michael Lynn \\ Ohio State University
}

Two explanations for the effects of alcohol on prosocial behavior-that is, mood enhancement and cognitive impairment-suggest that restaurant diners should tip more when they have consumed alcohol than when they have not. However, previous attempts to find a relationship between percent tip and alcohol consumption have failed. This failure may be due to statistical problems associated with using percent tip as a measure of tipping. This article reports a study that uses as a dependent variable residuals from a regression of bill size on tip amount. The results of this study indicate that alcohol consumption is positively related to tipping.

Alcohol consumption is known to affect a variety of antisocial behaviors (see Korytnyk \& Perkins, 1983; Lang, Goeckner, Adesso, \& Marlatt, 1975). Recently, alcohol has also been shown to increase prosocial behavior (Steele, Critchlow, \& Lui, 1985). There are at least two potential explanations for alcohol's effects on helping. First, alcohol improves people's moods (McCollan, Burish, Maisto, \& Sobell, 1980), and this positive affect may increase helping (see Isen \& Levin, 1972). Second, alcohol decreases people's ability to process information (Miller, Adesso, Fleming, Gino, \& Lauerman, 1978; Moskowitz \& DePry, 1968) and, in situations in which the most salient cues call for helping, this may reduce people's ability to process additional cues that would inhibit the behavior (see Steele \& Southwick, 1985).

Both of these explanations for alcohol's effects on helping suggest that alcohol should also increase the tips that restaurant patrons leave their servers. Restaurant diners' moods should be enhanced by alcohol and this enhanced affect should increase tipping. In addition, restaurant patrons generally face strong social pressures to leave a large tip that conflicts with their desires to minimize the cost of eating out. Assuming that the social pressures to tip are the most salient cues in tipping situations, alcohol should increase tips by weakening people's ability to process the additional cues that would ordinarily inhibit it. Inconsistent with these expectations, however, are the results of several 
studies failing to find an affect of alcohol consumption on tipping (Crusco \& Wetzel, 1984; Cunningham, 1979; Freeman, Walker, Borden, \& Latané 1975).

One possible explanation for this failure to find a relationship between alcohol consumption and restaurant tipping lies in the dependent measure of tipping used in these studies. All of the studies cited above used tip percentage as the dependent variable. Tip percentage is essentially a ratio of tip amount over bill size. The problem with this ratio is that it assumes the relationship between tip amount and bill size has a zero intercept, and this may not be true. If the intercept is positive, then dividing tip amount by bill size will create a spurious negative correlation between the quotient and the denominator-that is, between percentage of tip and bill size. It will also confound the relationship between tipping and the correlates of bill size such as alcohol consumption. For a fuller discussion of this, and other problems with using ratio variables, see Chayes (1971), Cohen and Cohen (1975), Pendleton, Newman, and Marshall (1983), and Schuessler (1974).

These problems with tip percentage as a dependent variable may explain why existing studies have failed to find an effect of alcohol consumption on restaurant tipping. This study reexamines the relationship between these variables by using as the dependent measure residuals from a regression of bill size on tip amount. These residuals control for the effects of bill size, while avoiding the statistical difficulties associated with using tip percentage.

Method

\section{Subjects}

The subjects in this study were 207 dining parties at a moderately priced Italian restaurant in a large midwestern city. 


\section{Procedure}

I was employed as a waiter in the restaurant studied and recorded information about all of my customers for a time period ranging from November 12 to December 16 . The variables that were recorded are listed and described below.

- Bill size: the total of each party's check(s) prior to any discounts from coupons or dining cards.

- Tip amount: how much I received in tips from each dining party.

- Alcohol: whether or not each party was served alcohol (no $=0$, yes $=1$ ).

- Number of drinks: how many alcoholic drinks (i.e., glasses of wine, beer, or cocktails) each party ordered.

- Group size: how many people (excluding infants) were in each dining party.

- Children: whether or not children were in each party (no $=0$, yes $=1$ ).

- Service structure: whether customers received buffet $(=0)$ or menu $(=1)$ service. Three parties eating meals off both the buffet and menu were coded as receiving menu service.

- Service: my classification of my service as good $(=1)$ or not so good $(=0)$ for each dining party. This classification was made before receiving the tip for all but 13 parties.

- Discount: whether or not each party got a discount by using a coupon or dining $\operatorname{card}($ no $=0$, yes $=1)$.

- Customer's gender: whether the persons paying each bill were male $(=0)$ or female $(=1)$. Five parties with both men and women paying bills were coded as having male payees. 
- Payment method: whether each party paid with credit $(=0)$ or cash $(=1)$. Four parties paying with both cash and credit were coded as cash customers.

Results and Discussion

\section{$\underline{\text { Tipping and Bill Size }}$}

The relationship between tipping and bill size was assessed in a regression of tip amount on bill size. The resulting equation (tip amount $=32$ cents $+11 \%$ of bill size) accounted for a statistically significant $50 \%$ of the variance in tip amount, $F(I, 205)=204.80, p<.0001$. The 32 -cent intercept is significantly different from zero, $\mathrm{t}(205)=2.30, \mathrm{p}<.03$. The addition of a quadratic component of bill size to this regression did not significantly improve the prediction of tip amount $F(I, 204)=.78$, ns. These results indicate that tipping is strongly, positively related to bill size. In order to control for this effect, the residuals from the linear regression of bill size on tip amount were used as the dependent measure in the analyses below.

\section{$\underline{\text { Tipping and Alcohol Consumption }}$}

The relationship between tipping and alcohol consumption was assessed in three analyses. First, a regression of residual tips on the linear and quadratic components of number of alcoholic drinks produced a significant positive effect of the linear component, $F(I, 204)=4.79, p<.03$. Second, a t-test on the difference in mean residual tips between parties that did and did not have alcohol indicated that the drinkers tipped more than the nondrinkers (18 cents versus -13 cents, $T[205]=3.05, p<.003$ ). Finally, a hierarchical multiple regression of residual tip on group size, children, service structure, service discount, customer's gender, payment method, alcohol, and number of drinks produced a significant effect for alcohol, $F(I, 197)=6.36, p<.02$, but not for number of drinks, $F(I, 197)=0.00$, ns. These results indicate that alcohol consumption does increase tipping and that this effect is reliable even after partialing out the effects of several other variables. 
The effects of the number of drinks ordered was weak relative to the effects of whether or not the party had any alcoholic drinks. This is probably because the number of drinks ordered was not necessarily related to how much the tipper drank. People in the party other than the person paying the bill and tip may have consumed most of the drinks ordered. However, the simple measure of whether or not a party was served alcohol probably does accurately reflect whether or not the tipper had alcohol. This is true because a party's alcohol order usually included drinks for everyone.

TABLE 1 Comparisons of Correlations Involving Residual Tip, Percent Tip, and Bill Size

\begin{tabular}{lcccc}
\hline & Residual Tip & \multicolumn{2}{c}{ Percent Tip } & Bill Size \\
\hline Bill size & - & $-.24^{* * *}$ & & - \\
Alcohol & $.21^{* * *}$ & $.15^{* *}$ & $(.06)^{\mathrm{a}}$ & $.24^{* * *}$ \\
Number of drinks & $.15^{* *}$ & .06 & $(.09)$ & $.30^{* * *}$ \\
Group size & .01 & -.09 & $(.10)$ & $.68^{* * *}$ \\
Children & $-.12^{*}$ & $-.18^{* * *}$ & $(.06)$ & $.28^{* * *}$ \\
Service structure & .09 & $.12^{*}$ & $(-.03)$ & .04 \\
Service & .07 & .09 & $(-.02)$ & -.02 \\
Discount & $-.13^{*}$ & $-.13^{*}$ & $(.00)$ & $.13^{*}$ \\
Customer's gender & -.01 & .05 & $(-.06)$ & $-.22^{* * *}$ \\
Payment method & .03 & .06 & $(-.03)$ & $-.12^{*}$ \\
\hline
\end{tabular}

a. Numbers in parentheses are the difference between the correlation coefficients of residual tip and of percent tip.

*Marginally significant at the .10 level; **significant at the .05 level; $* * *$ significant at the .01 level.

\section{$\underline{\text { Residual Tip Versus Percent Tip }}$}

In the introduction, it was argued that percent tip was a poor measure of tipping behavior because the use of ratio variables creates numerous spurious relationships. In order to provide direct evidence for this argument, all of the independent variables in this study were correlated with residual tip, percent tip, and bill size. The results are summarized in Table 1.

There are three things worth noting about these results. First, percent tip is significantly negatively correlated with bill size even though polynomial regressions of tip amount on bill size revealed only a positive linear relationship. This result supports the argument that dividing tip amount 
by bill size creates a spurious negative relationship between the quotient and the denominator. Second, the correlations involving bill size are related to the differences between the correlation coefficients of residual tip and of percent tip, $r(8)=.92, p<.001$. This supports the argument that the spurious relationship between percent tip and bill size also confounds the relationships between percent tip and the correlates of bill size. Finally, the effect of alcohol consumption on tipping was sizably reduced when percent tip was used as the dependent measure. Moreover, the relationship between tipping and the number of drinks was almost completely wiped out when percent tip was used.

These results support the possibility that previous studies may have failed to find an alcohol effect on tipping because their use of percent tip as an independent variable hid this relationship. This implies that previous research on restaurant tipping may be misleading and that additional research is needed to determine which of the earlier studies' results are valid.

\section{References}

Chayes, F. (1971). Ratio correlation. Chicago: University of Chicago Press.

Cohen, J., \& Cohen, P. (1975). Applied multiple regression/correlational analyses for the behavioral sciences. Hillsdale, NJ: Lawrence Erlbaum.

Crusco, A. H., \& Wetzel, C. G. (1984). The Midas touch: The effects of interpersonal touch on restaurant tipping. Personality and Social Psychology Bulletin, 10,512-517.

Cunningham, M. R. (1979). Weather, mood, and helping behavior: Quasi-experiments with the sunshine Samaritan. Journal of Personality and Social Psychology, 37, 1947-1956.

Freeman, S., Walker, M. R., Borden, R., \& Latan6, B. (1975). Diffusion of responsibility and restaurant tipping: Cheaper by the bunch. Personality and Social Psychology Bulletin, 1, 594-597.

Isen, A. S., \& Levin, P. (1972). The effects of feeling good on helping: Cookies and kindness. Journal of Personality and Social Psychology, 21, 384-388. 
Korytnyk, N., \& Perkins, D. (1983). Effects of alcohol versus expectancy for alcohol on the incidence of graffiti following an experimental task. Journal of Abnormal Psychology, 92, 382-385.

Lang, A., Goeckner, D., Adesso, V., \& Marlatt, G. (1975). Effects of alcohol on aggression in male social drinkers. Journal of Abnormal Psychology, 84, 508-518.

McCollan, J., Burish, T., Maisto, S., \& Sobell, M. (1980). Alcohol's effects on physiological aroused and self-reported affect and sensations. Journal of Abnormal Psychology, 89, 224-233.

Miller, M., Adesso, V., Fleming, J., Gino, A., \& Lauerman, P. (1978). Effects of alcohol on the storage and retrieval processes of heavy social drinkers. Journal of Experimental Psychology: Human Learning and Memory, 4, 246-255.

Moskowitz, H., \& DePry, D. (1968). Differential effect of alcohol on auditory vigilance and dividedattention tasks. Quarterly Journal of Studies on Alcohol, 29, 54-63.

Pendleton, B., Newman, I., \& Marshall, R. (1983). A Monte-Carlo approach to correlational spuriousness and ratio variables. Journal of Statistics and Computer Simulation, 18, 93-124.

Schuessler, K. (1974). Analysis of ratio variables: Opportunities and pitfalls. American Journal of Sociology, 80, 379-396.

Steele, C, Critchlow, B., \& Lui, T. J. (1985). Alcohol and social behavior: II. The helpful drunkard. Journal of Personality and Social Psychology, 48, 35-46.

Steele, C, \& Southwick, L. (1985). Alcohol and social behavior: I. The psychology of drunken excess. Journal of Personality and Social Psychology, 48, 18-34. 